WellBeing International

WBI Studies Repository

1997

\title{
Interactions among Dogs, People, and the Environment in Boulder, Colorado: A Case Study
}

\author{
Marc Bekoff \\ University of Colorado \\ Carron A. Meaney \\ Denver Museum of Natural History
}

Follow this and additional works at: https://www.wellbeingintlstudiesrepository.org/acwp_ca

Part of the Animal Studies Commons, Other Anthropology Commons, and the Social Psychology and Interaction Commons

\section{Recommended Citation}

Bekoff, M., \& Meaney, C. A. (1997). Interactions among dogs, people, and the environment in Boulder, Colorado: A case study. Anthrozoös, 10(1), 23-31.

This material is brought to you for free and open access by WellBeing International. It has been accepted for inclusion by an authorized administrator of the WBI Studies Repository. For more information, please contact wbisr-info@wellbeingintl.org.

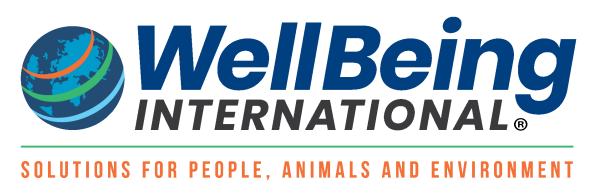




\title{
Interactions among Dogs, People, and the Environment in Boulder, Colorado: A Case Study
}

\author{
Marc Bekoff $^{1}$ and Carron A. Meaney ${ }^{2}$ \\ ${ }^{1}$ University of Colorado \\ ${ }^{2}$ Denver Museum of Natural History
}

\begin{abstract}
$\underline{\text { ABSTRACT }}$
From September 1995 to April 1996 we studied interactions among dogs, people, and the environment in Boulder, Colorado. Data on behavioral disturbances by off-leash dogs who were accompanied by a person were collected with respect to dog-dog and dog-human interactions, dog-wildlife encounters, dogs trampling vegetation, and dogs entering and disturbing bodies of water. A questionnaire also was administered. Behavioral data showed that off-leash dogs generally did not travel far off trail, that when they did it was for short periods of time, and that they rarely were observed to chase other dogs, disturb people, chase wildlife, destroy vegetation, or enter bodies of water. Results from analyses of the questionnaire (skewed toward non-dog owners) showed that dog owners and non-dog owners agreed that people were more disruptive to the environment than dogs and that unruly people were more problematic than unruly dogs. We conclude that the well-being and interests of dogs should not summarily and dismissively be compromised when dogs and people attempt to share limited space that can be used by all parties for recreational purposes. Indeed, a higher percentage of people reported that the quality of dogs' experience of the outdoors would be compromised more than their own enjoyment if dogs could not walk off-leash in areas where this is currently permitted. The methods used and the results from this case study can serve as a model for other locations in which dogs and people compete for limited spatial resources.
\end{abstract}

\section{INTRODUCTION}

Across the United States and in many other countries there is growing interest in how human and nonhuman animals (hereafter animals) can best share space that can be used by all parties for recreational purposes (see Knight and Gutzwiller 1995 for review). Although concern often focuses on the mutual well-being of humans and animals, when priorities have to be established, humans generally receive favorable treatment. Furthermore, when there are competing interests among humans, domestic dogs (Canis familiaris), wild animals, and "nature" in general, dogs' well-being and interests are often overridden (because they are "merely dogs" or "simply domesticated animals;" see Bekoff 1995, 1996a and Bekoff and Jamieson 1996 for discussion).

In the late 1800s, the people of Boulder, Colorado, had the foresight to set aside a large parcel of land backing into the foothills. Since then, additional land has been purchased under an Open Space program 
to create a greenbelt around the city, and to provide wildlife habitat and recreational opportunities. This program has been very successful and popular with the public.

In recent years, there has been a large increase in the use of Open Space trails in Boulder. As emphasized by Roberts (1995), Boulderites who enjoy the outdoors "love their parks to death" as they pursue recreational activities. This community resource, which is shared by humans and animals, consists of about 25,000 acres and approximately 150 miles of trails. In 1993 there were about 1.3 million visits, an increase of $13 \%$ compared to previous years (Miller 1994). In one study, it was reported that 21.3\% of groups visiting Boulder City Open Space participated in exercising their companion dogs (Zeller et al. 1994). In Boulder, as in other communities, companion animals such as dogs are very important to some people and problematic to others. The resulting conflicts between different groups (pro- and antidog factions) of people have placed the Boulder City Council in the position of having to consider various management decisions. Empirical data are necessary and can help to deal with controversial issues such as these in a more objective and straightforward manner. The development of sound management policies that attempt to maximize the well-being of all parties in recreational areas, including the possibility of placing restrictions on dogs, require detailed consideration of perceived and actual problems. Whereas there is a significant literature on human attitudes towards domestic and wild animals (e.g. Kellert 1994; Serpell 1995a,b, and references therein), there are very few data that can inform management decisions at the local level. As the number of humans and companion animals increases, existing land use problems continue to grow in Boulder (Roberts 1995; Zaslowsky 1995) and in other communities.

Among the major issues regarding land use in Boulder and other locales is the concern that off-leash dogs disturb other dogs, people, wildlife, and the environment. Some data support this claim (see Lowry and McArthur 1978, Gentry 1983, Mainini et al. 1993, Miller 1994, Knight \& Gutzwiller 1995, and references therein), whereas other data suggest either that dogs have a minimal demonstrable effect on animals such as deer (e.g. Progulske and Baskett 1958; Sweeney et al. 1971; Scott and Causey 1973) or that human impacts are equally or more invasive (e.g. Yalden and Yalden 1990). Clearly, the issues concerning the impact of dogs on wildlife and habitat require further and more detailed attention.

\section{METHODS}

Data were collected from September 1995 through April 1996 at six different locations in and around Boulder (four Open Space locations and on the University of Colorado, Boulder, campus and on the Pearl Street Mall). To achieve our goals of learning more about the behavior of off-leash dogs and about people's attitudes and perceptions towards dogs, we devised an original questionnaire and also collected detailed information on behavior. We felt that a combination of these two approaches should help to clarify distinctions between perceived problems and actual areas of conflict among dogs, people, and the environment.

\section{Questionnaires}

Our questionnaire (Appendix A) characterized the respondents by place of residence, patterns of use of Open Space, whether or not they owned and had a dog with them, their attitudes toward dogs and people, their experiences with dogs and people on Open Space, their views of the impact of dogs and people on habitat and wildlife, and their concerns about Open Space in the future. The questionnaire was developed and implemented with the input of professional pollsters and administered at the same four locations on Open Space at which data were collected on behavioral disturbances (Mt. Sanitas, Bobolink Trail, Chautauqua, Doudy Draw) where dogs are allowed to be off-leash, and also at two other locations (University of Colorado, Boulder Campus and Pearl Street Mall) where dogs are required to be on a leash. (Two other areas [Sawhill and Walden Ponds] received too little use to be included in the present 
data set.) All visitors with and without dogs were asked to fill out the questionnaire while the researcher waited for its completion. The questionnaires were analyzed by Market Research Services, Longmont, Colorado and cross-tabulations were run so that responses to each question could be correlated with one another.

\section{Behavioral Disturbances}

In this part of our study we were concerned with the following short-term and direct behavioral disturbances (for discussion, see Knight and Cole 1995, p. 61) by off-leash, companion dogs who were accompanied by a person. Data consisted of (i) characterization of the patterns of space use by individually observed dogs; (ii) characterization of patterns of chasing and flushing wildlife and disturbing vegetation and bodies of water; (iii) the nature of dog-dog encounters, and (iv) the nature of dog-people encounters.

Behavioral data were collected at six locations (see above). Observations were made "on trail" or from a stable vantage point, and efforts were made to minimize the effects of researchers' presence. For example, observers sat in the same place quietly and dogs generally paid little overt attention to them. At each location, beginning at the trailhead and extending for 500 meters $(\mathrm{m})$, the trail was partitioned with flagging into five linear $100 \mathrm{~m}$ sections. Other $100 \mathrm{~m}$ sections further along a trail were randomly sampled to see if there was any "trailhead effect."

Seven different people collected field data and administered the questionnaires. Regular meetings were held to make sure that there was consistency among the different researchers. Focal animal sampling (Altmann 1974), in which individual dogs were followed during their travels within each of the 100-meter sections, was used. All of the dog's activities and its location were recorded on prepared score sheets or read into a voice-activated tape recorder. A continuous time-base was maintained using stop watches. For each 100-meter section, we recorded the frequencies and rates with which dogs were "off trail" and "on trail," the distances from the trail that dogs travelled, and whether or not leaving the trail was ownerinduced (e.g. by throwing a Frisbee or a stick). We recorded all events of flushing and chasing, including and independent of the focal animal. We recorded observed instances when a dog did not appear to flush or to chase wildlife (recognizing that unobservable physiological changes can be caused by the presence of dogs; for discussion, see Gabrielson and Smith 1995). The mammalian species with which we were concerned included mule deer (Odocoileus hemionus), yellow-bellied marmots (Marmota flaviventris), black-tailed prairie dogs (Cynomys ludovicianus), rock squirrels (Spermophilus variegatus), jackrabbits (Lepus spp.), cottontails (Sylvilagus spp.), coyotes (Canis latrans), and red foxes (Vulpes vulpes). Avian species included black-billed magpies (Pica pica), robins (Turdus migratorius), dark-eyed juncos (Junco hyemalis), mallard ducks (Anas platyrhynchos), steller's jays (Cyanocitta stelleri), and mountain (Parus gambeli) and blackcapped chickadees (Parus atricapillus).

Data were analyzed using proportions tests (Bruning and Kintz 1977, p. 222ff) which generate the $z$ statistic. We used $p<0.05$ (two-tailed test; $z_{\text {crit }}>1.96$ ) to indicate significant differences between two percentages. The phrase "no significant difference" or similar terms mean that $z \leq 1.96$ and $p>0.05$. Critical values of $z$ for other levels of statistical significance are $2.58(p<0.010)$ and $3.30(p<0.001)$.

\section{RESULTS}

\section{Behavioral Disturbances}

Approximately 800 different dogs were observed for about a total of 150 hours. The behavior of dogs at different locations and at the same locale did not vary significantly (detailed analyses for the different locations are presented in Bekoff 1996b). Off-leash dogs generally travelled less than 2-5 $\mathrm{m}$ off trail for 
fewer than 1-2 minutes ( $\mathrm{min})$. For example, in one study ( $\mathrm{n}=100$ dogs) at Mt. Sanitas, $30(=30 \%)$ dogs remained on the trail and $45(=45 \%)$ dogs went off trail between $1-5 \mathrm{~m}$ for less than $1 \mathrm{~min}$. In a second study at Mt. Sanitas ( $\mathrm{n}=80$ dogs), $80 \%$ of dogs remained within $1-3 \mathrm{~m}$ of the trail (15\% remained on trail and $40 \%$ went less than $1 \mathrm{~m}$ off trail) and in a third study at Mt. Sanitas ( $\mathrm{n}=100$ dogs), $93(=93 \%)$ of dogs remained within $5 \mathrm{~m}$ of the trail. The general impression of observers was that when dogs went far off trail, they were lured off by the people who were responsible for them (e.g. people threw sticks, Frisbees, or went off trail and then called their dogs). It is also notable that only 2 "earnest chases" of wildlife (1 deer and 1 unidentified squirrel) were observed in which it was unambiguously concluded that it was the dog who initiated and maintained the chase. Dogs also only rarely entered bodies of water. Similar behavioral data were collected at Chautauqua ( $\mathrm{n}=272$ dogs). In addition, information on dog-dog interactions showed that 20/26 (81\%) were friendly (dogs greeted, sniffed, or played with one another) or neutral (dogs passed one another with no physical contact) and $6(19 \%$; $p<0.001)$ had aggressive (threat) components. All observers noted that dogs off leash were friendlier than dogs on leash, although no detailed data were collected on this aspect of behavior. We also observed 172 dog-people interactions of which 146 (85\%) were neutral and the rest $(n=26,15 \% ; p<0.001)$ were friendly. When sufficient data could be collected, they indicated that there were no differences in the behavior of dogs in different segments of the trail (1st $100 \mathrm{~m}$, 2nd 100m, 3rd 100m).

\section{Questionnaires}

Four hundred and fifty $(n=450)$ questionnaires were completed. More non-dog owners $(53.2 \%)$ than dog owners (46.8\%) were polled. Of all respondents, 96.4\% were comfortable with dogs, and there were no significant differences ( $p>0.05)$ among different locations or between dog owners and non-dog owners. Most people $(p<0.01)$ thought it would lessen the quality of their own $(68.3 \%)$ and their dog's $(82.2 \%)$ outdoor experience if dogs had to be leashed. In general, people were more disturbed by large dogs; breeds singled out as threatening ( $n=35$ respondents) included: Rottweilers (35.3\%), Doberman Pinschers (20\%), Pit Bull Terriers (17.1\%), and Chows (14.3\%). Many more people reported seeing other people disturb wildlife $(92.2 \%)$, vegetation $(78.0 \%)$, and bodies of water $(60.5 \%)$ significantly more often $(\mathrm{p}<0.001$ for all comparisons) than dogs $(49.7 \%, 31.4 \%$, and $9.0 \%$, respectively; Figure 1$)$.

While we did not detect any seasonal differences in water use by dogs, it is possible that in the hottest months of the year (when we were not in the field; June-August) they would disturb water more than at other times of the year.

Overall responses to the question "What do you think is the biggest problem facing those who use parks and open space?" are presented in Figure 2. This question was also analyzed separately for dog owners and non-dog owners. A small, but significantly higher percentage of non-dog owners thought that there were too many dogs $(10.6 \%)$ when compared to dog owners $(2.9 \% ; p<0.01)$, and a significantly higher proportion of non-dog owners (28.5\%) thought that there were too many piles of dog feces left on or near trails when compared to dog-owners $(19.5 ; p<0.05)$. Similar percentages $(p>0.05)$ of non-dog owners and dog owners reported that there were too many people (non-dog owners: $47.3 \%$; dog owners: $53.4 \%$ ), too many unruly dogs (15.5\%; $8.0 \%)$, and too many unruly people $(32.4 \% ; 28.2 \%)$. Both groups agreed that people, and not dogs, were the major problem. Regardless of location, respondents indicated that there were far too many people when compared to the number of dogs $(p<0.001)$ and too many unruly people when compared to the number of unruly dogs $(p<0.001)$. Disturbance by people included talking loudly, trampling vegetation, and littering.

Non-dog owners and dog owners were also asked what they thought about a number of different issues centering on purported problems with off-leash dogs. Similar proportions $(p>0.05)$ indicated that there should be standardized obedience tests for dogs (non-dog owners: $48.2 \%$; dog owners: $42.7 \%$ ), that 
dogs should not be banned from Open Space (93.3; 98.2\%), and that additional areas where dogs could run free should be established $(72.3 \% ; 64.3 \%)$. A significantly higher percentage of non-dog owners (55.0\%) when compared to dog owners (37.3\%) believed that there should be an annual fee for dogs using Open Space, that dogs should be on leashes at all times (30.5\%; 19.0\%), and that there should be stricter enforcement of voice and sight control (76.6\%; 66.0\%).

Figure 1. The percentage of positive ("yes") responses to the question "Have you seen wildlife, vegetation, streams, or other bodies of water disturbed by dogs or people?" (Questions 18-23, see Appendix A)

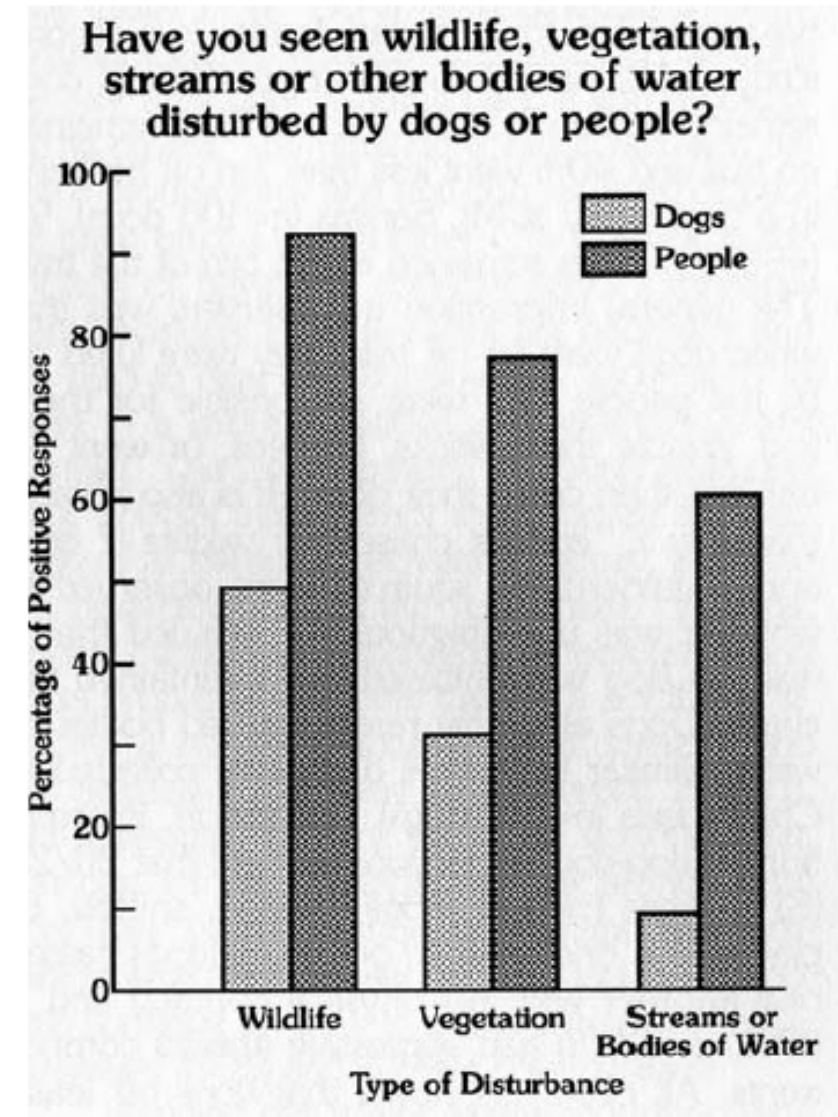

\section{DISCUSSION}

The present study was concerned with interactions among domestic dogs, people, and the environment in Boulder, Colorado. There were few noteworthy differences when data were analyzed by location. While some of the results may be specific to this area, there seems to be a more general message that deserves serious attention from those who live in other environs. There is no doubt that some dogs go off trail for various amounts of time and that some dogs do occasionally disturb people, wildlife, and habitat. However, compared to people, dogs did not seem to do much damage to vegetation or bodies of water, and they only rarely chased wildlife. Dog-wildlife encounters are very important to study; however, it is often very difficult to identify precisely what factors directly cause wildlife disturbances (Gentry 1983). People were more disruptive than were dogs, and when dogs did go far off trails they often were lured off by people. There was no trailhead effect and dogs' behavior differed little when they first were let free, during their travels in intermediate segments of a trail, and when they completed their walks. 
Figure 2. Responses to the question "What do you think is the biggest problem facing those who use parks and open space?" (Question 24, see Appendix A) Numbers total more than 100 because of some multiple responses.

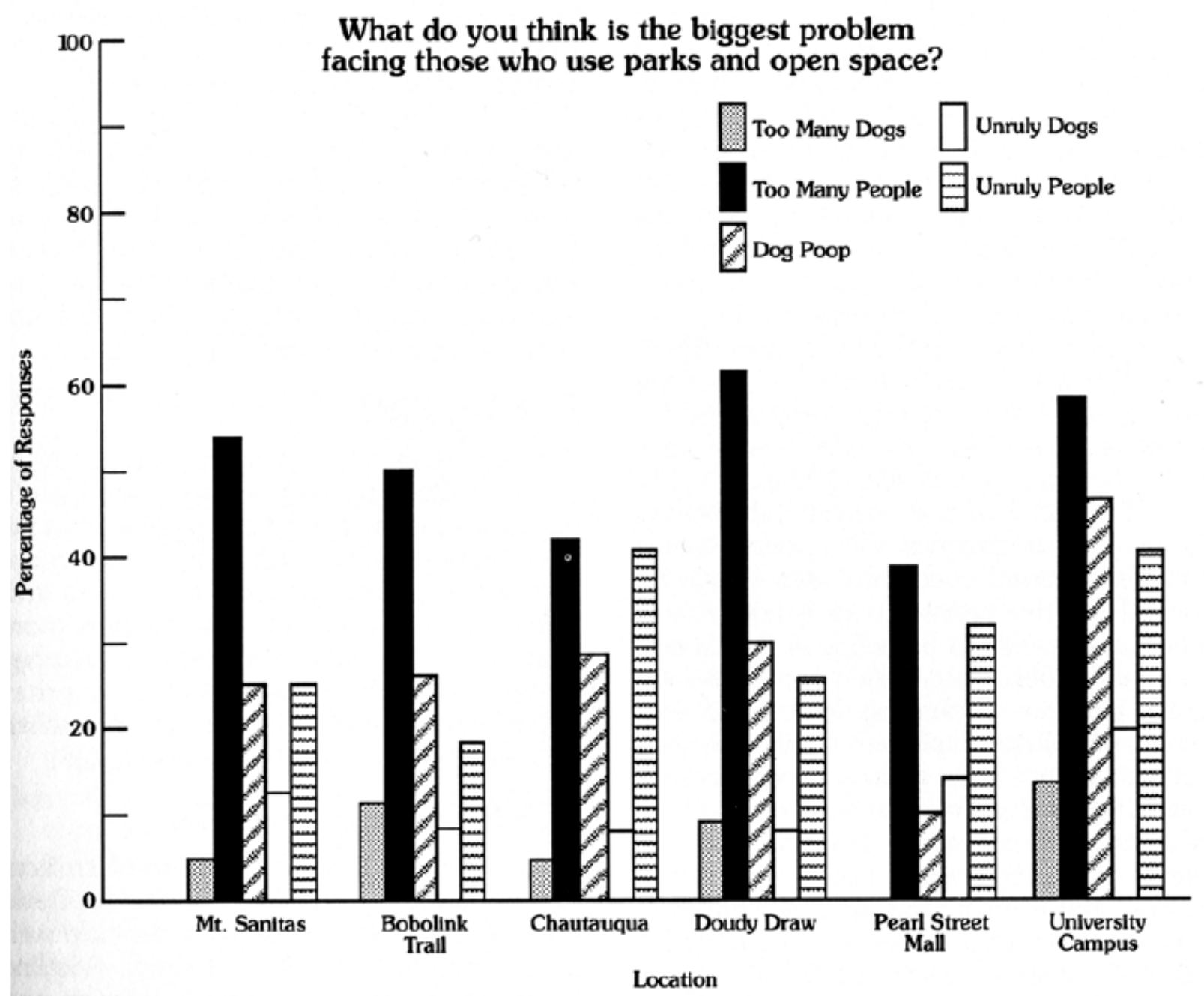

The results of the questionnaire support the behavioral data. In fact, the results of the questionnaire show clearly that dog owners and non-dog owners do not differ in their perceptions of major problemsessentially, too many people and too many unruly people using Open Space in Boulder. Almost $97 \%$ of people polled felt comfortable with dogs off-leash. People also reported (and direct observations confirmed the fact) that people disrupt wildlife more frequently than dogs, and people cause more damage to vegetation and to bodies of water. Less than one-third of the respondents reported that feces were a problem. There are many reasons why feces can cause problems (e.g. hygienic, environmental, aesthetic; Beck 1979) and perhaps they are more of a problem in urban areas (Dumont 1996) than in open recreational areas. Boulder is dealing with this problem by placing plastic bags and trash cans near trailheads and along trails. Interestingly, non-threatening barking by dogs was not an issue for either group. Also, all observers noted that dogs off leash were friendlier than dogs on leash, although no detailed data were collected on this aspect of behavior (see also Thomas 1996).

The relationship between people and dogs has changed greatly in Boulder over the past 25 years. In the early 1970s many uncastrated dogs ran free without their owners. Dogs occasionally formed packs, 
chased deer and, on at least one occasion, attacked a child. Since then, there appears to have been an increased interest in having well-behaved dogs. In 1980, the Boulder Humane Society regularly offered one obedience class, and in 1996 there are 20 concurrent classes (Nana Wills, personal communication). Dog owners have become more responsible (having their dogs castrated and watching over them more conscientiously), and rarely is a dog seen without their owner or another person in attendance.

We conclude that little needs to be done to manage dogs directly in the areas where we conducted our studies. There are always going to be "problem" dogs and "problem" people. In Boulder and perhaps in other areas, reports of unruly dogs seem to attract a lot of attention, but of course, people do not report when dogs are well-behaved. Additional enforcement may solve some problems but there really are few problems that could not largely be solved by continuing serious efforts to educate people about dog behavior and matters of etiquette and responsibility (see also Beck 1996 and Dumont 1996), and by requiring people to learn more about dog behavior and control of their companions, for people and their companions essentially are a cooperative social unit (Sanders 1990).

The fact that dog owners and non-dog owners did not disagree on important issues (that standardized obedience tests should be required and that banning dogs is not a viable option) also needs to be addressed. Although standardized obedience testing is possible and equally attractive to non-dog owners and dog-owners alike, the implementation of such a practice has not been given serious attention. While the details still need to be worked out for different locations, some possibilities would entail having people attend classes, hire a professional trainer, or train their dogs themselves and then go to their local humane society for testing. A set fee would be established to cover the cost of testing and licensing; the fee might also include a donation to the society.

Further concerns could be addressed by having various stipulations that could cover different sorts of violations. The following suggestions might be helpful for implementing obedience certification. People who were first-time offenders who did not have a license would be given a certain amount of time to complete the standardized test and pay a small fine. First-time offenders who had already received their licenses would have to pay for, and repeat, the standardized test within a certain period of time, but there would be no fine. However the obedience certification process is implemented, there seems to be little doubt that dogs and people would benefit.

It seems clear to us that the well-being and interests of dogs should not summarily be compromised when dogs and people attempt to share limited space that can be used by all parties for recreational purposes. The methods used and the results from this case study can serve as a model for other locations in which dogs and people compete for limited spatial resources.

\section{POSTSCRIPT}

A recent study of dogs on the University of Colorado (Boulder) campus (Dwyer and Bekoff, unpublished data) showed that leashed dogs initiated contact with humans 5.5 times more than did unleashed dogs, and that people initiated contact with leashed dogs 3.8 times more than with unleashed dogs. Generally, unleashed dogs ignored humans and choose other unleashed dogs with whom to interact when they were not exploring their surroundings.

\section{ACKNOWLEDGMENTS}

We thank Carrie Kull, Ed Leigh, Ron Hamilton, Kristen Gacek, Shelese Pratt, Gary Renne, David Fenyvesi, and Deborah Sapienza for help with data collection, and Myanna Lahsen, Rosalind Yanishevsky, Clint Miller, Ann Wichmann, and Andrew Smith for help with the development of the questionnaire. Rosalind Yanishevsky, Colin Allen, Alan Beck, Robert Eckstein, Ann Wolfe, and an 
anonymous reviewer provided helpful comments on an ancestral version of this manuscript. Rosalind Yanishevsky suggested how implementation of standardized testing might be initiated. We received financial support from an anonymous donor and the Department of EPO Biology, University of Colorado, Boulder.

\section{REFERENCES}

Altmann, J. 1974. Observational study of behaviour: Sampling methods. Behaviour 49:227-267.

Beck, A. M. 1979. The impact of the canine clean-up law. Environment 28:28-31.

Beck, A. 1996. Ecological aspects of urban stray dogs. In Readings in Companion Animal Behavior, 259263, ed. V. L. Voith and P. L. Borchelt. Trenton, New Jersey: Veterinary Learning Systems.

Bekoff, M. 1995. Marking, trapping, and manipulating animals: Some methodological and ethical considerations. In Wildlife Mammals as Research Models: In the Laboratory and Field, 31-47, ed. K. A. L. Bayne and M. D. Kreger. Greenbelt, Maryland: Scientists Center for Animal Welfare.

Bekoff, M. 1996a. Naturalizing and individualizing animal well-being and animal minds: An ethologist's naiveté exposed? In Wildlife Conservation, Zoos, and Animal Protection: Examining the Issues, 63-129, ed. A. Rowan. Medford, Massachusetts: Tufts University Press.

Bekoff, M. 1996b. Preliminary report on dogs and people in Boulder. Unpublished paper.

Bekoff, M., and Jamieson, D. 1996. Ethics and the study of carnivores: Doing science while respecting animals. In Carnivore Behavior, Ecology, and Evolution, Vol. 2. 15-45, ed. J.L. Gittleman. Ithaca, New York: Cornell University Press.

Bruning, J. L., and Kintz, B. L. 1977. Computational Handbook of Statistics, Glenview, Illinois: Scott, Foresman and Company.

Dumont, G. 1996. A telephone survey on attitudes of pet owners and non-owners to dogs and cats in Belgian cities. Anthrozoös 9:19-24.

Gabrielson, G. W. and Smith, E. N. 1995. Physiological responses of wildlife to disturbance. In Wildlife and Recreation: CoexistenceThrough Management and Research, 95-107, ed. R. L. Knight and K.J. Gutzwiller. Washington, D.C.: Island Press.

Gentry, C. 1983. When Dogs Run Wild: The Sociology of Feral Dogs and Wildlife, Jefferson, North Carolina: McFarland \& Company, Inc., Publishers.

Kellert, S. R. 1994. Attitudes, knowledge and behaviour toward wildlife among the industrial superpowers: The United States, Japan and Germany. In Animals and Human Society: Changing Perspectives, 166-187, ed. A. Manning and J. Serpell. New York: Routledge.

Knight, R. L. and Cole, D. N. 1995. Factors that influence wildlife responses to recreationists. In Wildlife and Recreation: Coexistence Through Management and Research, 71-79, ed. R. L. Knight and K.J. Gutzwiller. Washington, D.C.: Island Press.

Knight, R. L. and Gutzwiller, K. J. (eds.) 1995. Wildlife and Recreation: Coexistence Through Management and Research, Washington, D.C.: Island Press.

Lowry, D. A. and McArthur, K. L. 1978. Domestic dogs as predators on deer. Wildlife Society Bulletin 6:38-39.

Mainini, B., Neuhaus, P. and Ingold, P. 1993. Behaviour of marmots Marmota marmot under the influence of different hiking activities. Biological Conservation 64:161-164.

Miller, C. K. 1994. Environmental impacts of passive recreational trails in riparian areas. Proceedings of the 6th Annual Colorado Riparian Association Conference, USA, 12 pages.

Progulske, D. R. and Baskett, T. S. 1958. Mobility of Missouri deer and their harassment by dogs. Journal of Wildlife Management 22:184-192.

Roberts, C. 1995. Boulderites love parks to death. Boulder Daily Camera, 6 November, 1C.

Sanders, C. R. 1990. Excusing tactics: Social responses to the public misbehavior of companion animals. Anthrozoös 4:82-90. 
Scott, M. D. and Causey, K. 1973. Ecology of feral dogs in Alabama. Journal of Wildlife Management 37:253-265.

Serpell, J. (ed.) 1995a. The Domestic Dog: its Evolution, Behaviour and Interactions with People, New York: Cambridge University Press.

Serpell, J. 1995b. From paragon to pariah: some reflections on human attitudes to dogs. In The Domestic Dog: its Evolution, Behaviour and Interactions with People, 245-256, ed. J. Serpell. New York: Cambridge University Press.

Sweeney, J. R., Marchinton, R. L. and Sweeney, J. M. 1971. Responses of radio- monitored white-tailed deer chased by hunting dogs. Journal of Wildlife Management 35:707-716.

Sylvan, R. and Bennett, D. 1994. The Greening of Ethics: From Anthropocentrism to Deep-Green Ecology, Tucson: University of Arizona Press.

Thomas, E. M. 1996. Canine liberation. New York Times 1 May, page A19.

Yalden, P. E. and Yalden, D. W. 1990. Recreational disturbance of breeding golden plovers Pluvialis apricarius. Biological Conservation 15:243-262.

Zaslowsky, D. 1995. The battle of Boulder. Wilderness Summer: 25-33.

Zeller, M., Zinn, H. C. and Manfredo, M. J. 1994. Boulder Open Space Visitation Study. Unpublished manuscript. 


\section{APPENDIX A: QUESTIONNAIRE}

\section{Perceptions of the Impact of Dogs on Open Space}

We are interested in learning more about how dogs and people use open space so that dogs and people can maximize the pleasure that can be had by being outdoors in the limited available space. We hope that you will take the time to answer these questions.

Date: Location: Time: Sex: Age: Children?

(1) Do you live in Boulder? City County For how long? No

(2) How often do you use open space? (a) daily, (b) 5 times per week, (c) 2-4 times per week, (d) 2-4 times per month, (e) less than 1 time per month, (f) 2-4 times per year or less, (g) never

(3) How long have you used this portion of open space?

(4) Why do you come to open space? (a) to exercise myself, (b) to exercise my dog, (c) to see wildlife, (d) to be alone, (e) to enjoy nature, (f) other

Please rank your top three (3) choices by writing down the appropriate letter:

(5) In what type of activity do you usually engage? (you can choose more than 1) (a) walk/hike, (b) jog/run, (c) bicycle, (d) equestrian, (e) exercise dog)

(6) Are you a dog owner? Yes:___ No:

(7) Are you comfortable with dogs? Yes:__ No:

(8) Do you have a dog with you now? Yes: No: On leash: Off Leash: excellent voice control: Under control most of the time: Not well-controlled: Under

(9) Do you think dogs should be (a) on leash always, (b) off leash always if dog not a threat to people, (c) off leash in certain areas and at certain times, (d) other?

(10) Would it lessen the quality of your open space experience if your dog had to be on a leash? Yes: No:

How:

(11) Would it lessen the quality of your dog's experience if your dog had to be on a leash? leash? Yes: No:

How:

(12) Have you ever been attacked by a dog on open space? (a) two or more times, (b) once, (c) never. What were extent of injuries?

(13) Have you ever felt uneasy when passing someone else's dog? (a) two or more times, (b) once, (c) never.

(14) In what ways did you feel uneasy? (a) disturbs me, (b) disturbs children,(c) disturbs my dog, (d) disturbs wildlife, (e) too many dogs, (f) dog out of control 
(15) Do certain types of dogs bother you more than others? Yes: No: If YES, why: Please provide more details next to your choices
(a) breed
(b) size
(c) color
(d) behavior
(e) sex

(f) the behavior of the person with the dog?

(16) Have you ever felt uneasy in the presence of other people on open space? (a) two or more times, (b) once, (c) never.

(17) Have you seen other people bothered by dogs? (a) two or more times, (b) once, (c) never.

(18) Have you seen wildlife disturbed by dogs? Yes: No:

If YES, (a) often, (b) occasionally, (c) never

(19) Have you seen wildlife disturbed by people? Yes: No:

If YES, (a) often, (b) occasionally, (c) never

(20) Have you seen vegetation disturbed by dogs in a harmful way? Yes: No: If YES, (a) often, (b) occasionally, (c) never

(21) Have you seen vegetation disturbed by people in a harmful way? Yes: No: If YES, (a) often, (b) occasionally, (c) never

(22) Have you seen streams or other bodies of water disturbed by dogs in a harmful way? Yes: No:

If YES, (a) often, (b) occasionally, (c) never

(23) Have you seen streams or other bodies of water disturbed by humans in a harmful way? Yes: No:

If YES, (a) often, (b) occasionally, (c) never

(24) What do you think is the biggest problem facing those who use open space?

Too many dogs:

Too many unruly dogs:

Too many people: 
Too many unruly people:

Too much dog poop:

Other:

Comments:

(25) If findings suggest that dogs are problematic, do you agree with:

(a) requiring standardized obedience testing for dogs off leash: Yes:

No:

(b) requiring annual fee and tags for dogs using open space: Yes:

No:

(c) requiring all dogs to be on a leash at all times: Yes:

No:

(d) requiring stricter enforcement for voice and sight control: Yes: No:

(e) banning all dogs: Yes: No:

(f) providing areas for dogs on leash and other areas for dogs off leash? Yes: No:

(g) other

\section{General Comments}

